\title{
PEMBANGUNAN KOMIK STEM TAHUN SATU UNTUK MATAPELAJARAN SAINS DAN MATEMATIK
}

\section{DEVELOPMENT A YEAR ONE STEM COMIC FOR SCIENCE AND MATHEMATICS SUBJECTS}

\author{
${ }^{1}$ Norazilawati Abdullah, ${ }^{2}$ Mazlini Adnan, ${ }^{3}$ Laili Farhana Ibharim, ${ }^{4}$ Tan Wee Hoe, \\ ${ }^{5}$ Dahlia Janan, ${ }^{6}$ Jafri Malin Abdullah, ${ }^{7}$ Noorzeliana Idris, ${ }^{8}$ Amila Saliza Abdul Wahab \\ $1,2,3,4,5$ Universiti Pendidikan Sultan Idris, \\ ${ }^{6}$ Universiti Sains Malaysia, \\ ${ }^{7,8} \mathrm{Kementerian}$ Pendidian Malaysia \\ *emel : nora@fpm.upsi.edu.my
}

Received : 18 Oktober 2018; Accepted : 30 November 2018; Published : 29 Disember 2018

\begin{abstract}
Abstrak
Kajian ini bertujuan untuk membangunkan Komik STEM tahun satu untuk mata pelajaran sains dan matematik. Komik STEM ini dibangunkan berdasarkan kepada model Pengetahuan Teknologi, Pedagogi dan Kandungan (TPACK). Pembangunan kandungan komik ini melibatkan dua fasa iaitu fasa pembinaan komik STEM dan fasa penilaian Komik STEM. Walaubagaimanapun, artikel ini hanya membincangkan kepada fasa pembangunan komik STEM. 13 orang Guru Cemerlang sains dan matematik dari daerah Hulu Langat terlibat dalam analisis sukatan mata pelajaran sains dan matematik tahun satu dan penyediaan skrip manakala ilustrator komik STEM dibuat oleh 2 orang pensyarah dari Fakulti Seni. Komputeran dan Industri Kreatif dari Universiti Pendidikan Sultan Idris. Hasilnya, sebuah Komik STEM yang mengandungi 10 siri gabungjalin kandungan tajuk dalam matapelajaran sains dan matematik tahun satu telah berjaya dibangunkan. Komik ini dijangka menarik minat serta meningkatkan pencapaian murid tahun satu dalam matapelajaran sains dan matematik. Implikasi kajian ini, komik STEM boleh digunakan oleh guru sebagai bahan bantu mengajar sains dan matematik.
\end{abstract}

Kata kunci Pembangunan, Komik STEM, Murid Tahun Satu, Sains dan Matematik.

\begin{abstract}
This study aims to develop a year one STEM Comic for science and mathematics subjects. The STEM comic was developed based on the Technology Knowledge, Pedagogy and Content (TPACK) model. The
\end{abstract}


development of this comic involves two phases which is development phase and assessment phase. However, this article only discusses the development phase of STEM comic. 13 Excellent teachers of science and mathematics from the Hulu Langat district were involved in the analysis of syllabus year one science and mathematics subjects and the preparation of scripts while the STEM comic illustrator was created by two lecturers from the Faculty of Art, Computing and Creative Industry from the Sultan Idris Education University. As a result, a STEM comic that contains 10 series for year one science and mathematics subjects has been successfully developed. This comic is expected to attract and enhance the achievement of year one students in science and mathematics. Implication of this study, STEM comic can be used by teachers as science and mathematics teaching aids.

Keywords Development, STEM Comic, Year One Students, Science and Mathematics.

\section{PENGENALAN}

Istilah STEM mula diperkenalkan di Amerika Syarikat pada 1990-an. Pada asalnya STEM disebut dengan akronim SMET untuk mewakili Sains, Matematik, Kejuruteraan dan Teknologi (Sanders, 2009). Di Malaysia, kronologi pendidikan STEM sebenarnya telah bermula lebih awal daripada yang kita sangkakan. Walaupun kini pendidikan STEM hangat diperkatakan, sebenarnya Malaysia telah berusaha mengetengahkan sains dan teknologi sejak dari tahun 60-an lagi (Rajah 1). JKPPT (1967) telah mengesyorkan unjuran nisbah murid peringkat menengah atas ialah 2:3 (40:60) bagi aliran sastera berbanding aliran Sains dan Teknik mulai tahun 1970. Pembelajaran bersepadu merangkumi disiplin Sains, Teknologi, Kejuruteraan dan Matematik yang mengaplikasikan konteks dunia sebenar dengan menghubungkan institusi pendidikan, komuniti dan industri untuk melahirkan bakat dan masyarakat berliterasi STEM. Seterusnya, pembangunan pendidikan STEM di Malaysia jelas kelihatan signifikan dalam Pelan Pembangunan Pendidikan Malaysia(PPPM) 2013-2015 (Kementerian Pendidikan Malaysia (KPM), 2013). PPPM tersebut telah menyediakan pembaharuan dalam pendidikan STEM dan dibahagikan kepada tiga fasa.

Fasa Pertama (2013-2015): Mengukuhkan kualiti pendidikan STEM melalui pengukuhan kurikulum, pengujian dan latihan guru, dan penggunaan model pembelajaran pelbagai mod (blended learning). Fasa kedua (2016-2020): Menarik minat dan kesedaran masyarakat dalam STEM melalui kempen dan kerjasama dan fasa ketiga (2021-2025) : penilaian ke atas kejayaan inisiatif dua peringkat pertama dan pembangunan pelan masa depan dengan inisiatif dan program baru. Kerjasama Kementerian Sains, Teknologi dan Inovasi bersama Kementerian Pendidikan dan Kementerian Pengajian Tinggi, satu pelan tindakan yang dinamakan Pelan Tindakan STEM Nasional 2017-2025 telah dibangunkan bagi menyokong usaha menyemarakkan aktiviti STEM khususnya di Malaysia. Justeru, boleh dikatakan Pendidikan STEM telah menjadi trend utama dalam dunia pendidikan global. Didapati negara yang membangun 
dengan pesat, bilangan murid yang terlibat dalam pendidikan STEM adalah ramai dan dasar pembangunan negara juga adalah berfokus kepada pembangunan STEM untuk menghasilkan orang yang berbakat dalam bidang STEM. Usaha ini adalah demi pembangunan ekonomi negara supaya dapat bersaing di platform antarabangsa.

\section{TINJAUAN LITERATUR}

Hari ini telah menjadi satu perbincangan yang hangat bagaimana untuk mengintegrasikan keempat-empat bidang Sains, Teknologi, Kejuruteraan dan Matematik dalam pendidikan untuk melaksanakan pendidikan STEM. Ramai penyelidik dalam pendidikan STEM telah mengemukakan pandangan yang berlainan. Menurut laporan yang dikemukakan oleh Hanover Research pada tahun 2012, semakin ramai penyokong pendidikan STEM menyokong sifat saling berkaitan semua mata pelajaran dalam STEM dan keperluan melaksanakan pendekatan antara disiplin dan bukannya menganggap mata pelajaran itu sebagai satu subjek "silo" atau subjek yang berdiri sendiri.

Menurut Sanders (2009), integrasi pendidikan STEM temasuklah menggunakan pendekatan yang meneroka pengajaran dan pembelajaran antara mana-mana dua atau lebih daripada dalam bidang STEM atau antara mata pelajaran dalam STEM. Dalam laporan Sanders (2009) juga telah menyatakan bahawa pelaksanaan pengintegrasian dalam empat bidang pendidikan STEM memerlukan kerjasama yang erat dalam kalangan guru STEM, komitmen guru STEM dan sokongan pihak pentadbir sekolah dengan kaedah penyelesaian masalah yang pelbagai.

Pengintegrasian STEM adalah pendekatan pengajaran pengabungjalinan mata pelajaran, malah halangan antara empat disiplin ilmu telah dikeluarkan (Mazlini et al., 2016). Pengintegrasian Sains, Teknologi, Kejuruteraan dan Matematik (STEM) membantu murid menghubungkan kemahiran yang berkaitan dengan penggunaan kemahiran dalam aplikasi dunia sebenar dengan menyediakan konteks pembelajaran yang berharga (Brophy, Klein, Portsmor \& Rogers, 2008). Daripada kajian, laporan penyelidik dan pakar-pakar ini, dapat membuat kesimpulan bahawa melaksanakan pengajaran pendidikan STEM mesti melibatkan pengintegrasian mata pelajaran-mata pelajaran dalam STEM, sama ada dua mata pelajaran atau lebih.

Menurut Morrison (2006), pendidikan sains, teknologi, kejuruteraan dan matematik (STEM) sering dipanggil meta-disiplin, penciptaan disiplin berdasarkan integrasi pengetahuan disiplin menjadi satu pengetahuan 'keseluruhan' yang baru. Ini telah merapatkan disiplin di kalangan disiplin diskret kini dan dianggap sebagai satu entiti yang dikenali sebagai STEM. Mata pelajaran dalam STEM adalah berkait rapat antara satu sama lain dan pengintegrasi mata pelajaran ini boleh membantu pelajar membangunkan pengetahuan, konsep dan kemahiran. Pengintegrasian Sains, Teknologi, Kejuruteraan dan Matematik (STEM) dapat membantu murid menghubungkan kemahiran yang berkaitan dengan penggunaan dalam aplikasi dunia sebenar dengan menyediakan konteks pembelajaran yang bernilai (Brophy, Klein, Portsmor \& Rogers, 2008).

Dalam kajian pengintegrasian pendidikan STEM, Lynn, Tamara, Carla dan Gillian (2016) telah menyatakan lima ciri-ciri teras yang membezakan pengintegrasian pendidikan STEM. Lima ciri tersebut adalah: (1) kandungan dan amalan satu atau 
lebih utama dalam disiplin sains dan matematik menentukan beberapa matlamat pembelajaran utama; (2) pengintegrasian ialah amalan kejuruteraan dan kejuruteraan reka bentuk teknologi sebagai konteks dan/ atau komponen kandungan antarabangsa yang akan dipelajari; (3) reka bentuk kejuruteraan atau amalan kejuruteraan yang berkaitan dengan teknologi memerlukan penggunaan konsep sains dan matematik memberikan justifikasi terhadap reka bentuk dicipta; (4) pembangunan kemahiran abad ke-21 ditekankan; (5) konteks pengajaran memerlukan penyelesaian masalah dunia sebenar atau tugasan melalui kerja berpasukan (Rodger, 2013).

Pengintegrasian pendidikan STEM bukan bermaksud mewujudkan satu mata pelajaran yang baharu di sekolah. Pengintegrasian pendidikan STEM di dalam bilik darjah adalah sejenis integrasi kurikulum. Konsep integrasi kurikulum adalah kompleks dan mencabar, integrasi mata pelajaran adalah lebih daripada suatu perkara yang hanya meletakkan bidang mata pelajaran yang berbeza secara bersama-sama. Idea integrasi kurikulum berasal dari kesedaran pendidik bahawa masalah dunia sebenar tidak dibahagikan kepada disiplin ilmu yang diajar secara berasingan di sekolahsekolah (Czerniak et al. 1999). Dalam kebanyakan keadaan dan kajian kes, pendidik yang merentasi kurikulum ini memerlukan kemahiran-kemahiran tertentu. Misalnya, kemahiran pengetahuan kandungan mata pelajaran tersebut, kemahiran pedagogi dan kemahiran teknologi dan kejuruteraan.

Komik atau juga dikenali sebagai grafik novel semakin mendapat perhatian di kalangan pendidik untuk digunakan dalam bidang akademik dan pendidikan. Menurut Cleaver (2008), sesetengah guru mula melihat komik sebagai alat pendidikan yang berpotensi untuk membangkitkan minat pelajar dalam mata pelajaran akademik. Novel-novel grafik telah digunakan untuk mengajar pelbagai bidang seperti mengajar isu-isu sosial (Tabachnik, 2009), di dalam kelas bahasa Inggeris untuk pelajar ESL belajar Bahasa Inggeris (Boatright 2010), dan juga untuk pengajaran sains matematik di peringkat rendah dan peringkat sekolah menengah (Chipman 2010).

Menurut Miller (2005), penggunaan komik merupakan medium yang berkesan dalam mengintegrasikan pelbagai bidang untuk mecapai objektif yang diingini. Kenyataan ini turut disokong oleh Tilley (2008), apabila menyatakan penggunaan komik dalam pendidikan merupakan satu cara untuk meningkatkan literasi pelajar mereka. Ini kerana novel grafik menawarkan nilai, variasi dan pendekatan baru yang diakui mempunyai kesan visual yang baik dalam menarik minat golongan muda terhadap sesuatu konteks, bahkan ia juga sangat berguna untuk digunakan dalam merentasi kurikulum, di samping menawarkan alternatif kepada penggunaan kaedah tradisional seperti teks dan media massa yang lain (Schwarz, 2002).

Selain mendedahkan pembaca kepada kepelbagaian bidang dalam satu naskah, penggunaan komik dalam pendidikan juga dapat mendedahkan pembaca kepada pelbagai maklumat dan perbendaharaan kata yang baru. Ini dapat meningkatkan minat murid-murid untuk medalami ilmu yang diketengahkan dalam jalan penceritaan sesebuah komik. Penggunaan komik dalam pembelajaran juga memberi peluang kepada murid-murid untuk mengeksplorasi dan meningkatkan kemahiran berfikir secara krtitikal. Kelebihan inilah yang akan diperolehi oleh murid-murid apabila komik STEM sains dan matematik digunakan dalam pembelajaran, dan ia pasti akan membawa impak yang positif seperti yang dinyatakan oleh Gavigan dan Kimmel 
(2013) bahawa penggunaan novel grafik akan membawa perubahan positif dalam kehidupan literasi pelajar-pelajar.

\section{METODOLOGI KAJIAN}

Metodologi kajian ini terbahagi kepada dua fasa. Fasa pertama adalah pembinaan Komik STEM manakala fasa kedua adalah pengujian komik tersebut. Walaubagimanapun, penulisan artikel ini hanya memfokuskan kepada fasa pembangunan.

\section{Fasa Pembinaan Komik STEM}

Fasa pembinaan Komik STEM menggunakan model TPACK seperti Rajah 1 bermula dengan penyediaan kandungan pengetahuan dan pedagogi yang melibatkan 13 orang guru cemerlang sains dan matematik daerah Hulu Langat. Empat topik bagi matapelajaran sains dan lima topik bagi matapelajaran matematik penggal kedua telah dipilih daripada Dokumen Standard Kurikulum dan Pentaksiran (DSKP), Kurikulum Standard Sekolah Rendah (KSSR) seperti yang ditunjukkan pada Jadual 1. Penjajaran konstruktif kandungan pengetahuan dan pedagogi antara matapelajaran sains dan matematik dilaksanakan terlebih dahulu sebelum pemetaan jalan cerita komik dilakukan. Dalam komik ini, terdapat lima watak utama iaitu Profesor Megat Adam (Neuro-Gardener Sifoo), Megat Amir (Neuron Man), Puteri Hanna (Neuron Woman), Megat Alif(Neuron Boy) dan Puteri Sarah (Neuron Girl). Dari aspek teknologi, ilustrasi Komik STEM diterjemahkan dalam bentuk komik hasil daripada jalan cerita. Ilustrator yang terdiri daripada pensyarah UPSI menggunakan perisian Adobe Photoshop dan Adobe Ilustrator. Komik STEM melalui proses semakan dari aspek laras bahasa dan grafik yang bersesuaian mengikut piawaian Kementerian Pendidikan Malaysia (KPM).

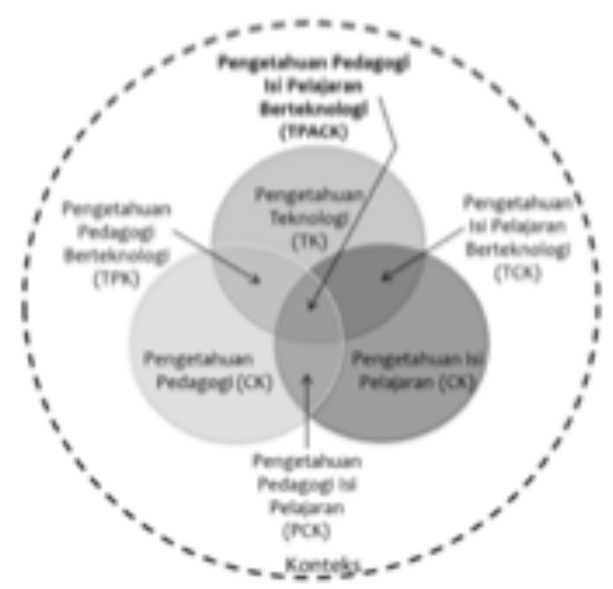

Rajah 1 Model Pengetahuan Teknologi, Pedagogi dan Kandungan (Muhammad Jailani \& Siti Raihana, 2016) 
Jadual 1 Topik Matapelajaran Sains dan Matematik

\begin{tabular}{lccc}
\hline \multicolumn{1}{c}{ Sains } & Siri & Matematik & Siri \\
\hline $\begin{array}{l}\text { Binaan daripada bongkah } \\
\text { bentuk asas }\end{array}$ & Siri 1, 2 dan 3 & Ruang & Siri 1 \\
Penyerapan & Siri 4, 5 dan 6 & Hari dan bulan, muka jam & Siri 2 \\
Tanah & Siri 7 dan 8 & Pengurusan data & Siri 3 \\
Bentuk muka bumi & Siri 9 & $\begin{array}{c}\text { Ukuran sukatan } \\
\text { Bentuk dua dimensi }\end{array}$ & $\begin{array}{c}\text { Siri 4, 5, 6, } 7 \\
\text { Siri } 9\end{array}$ \\
\hline
\end{tabular}

\section{DAPATAN KAJIAN}

Komik STEM yang telah dihasilkan telah dijilid dan mengandungi 103 mukasurat. Berikut adalah ringkasan Komik STEM yang telah dihasilkan. Terdapat 10 siri dalam komik ini termasuk satu siri pengenalan. Setiap satu mempunyai temanya yang tersendiri. Berikut disertakan tema bagi setiap siri:

Siri Pengenalan

Siri 1 - Taman Permainan

Siri 2 - Selamat Hari Jadi Sarah

Siri 3 - Bulan Panitia Sains dan Matematik

Siri 4 - Hujan Oh Hujan

Siri 5 - Sukaneka

Siri 6 - Busuknya

Siri 7 - Projek Kebun Sayur

Siri 8 - Balik Kampung

Siri 9 - Berkelah di Port Dickson

Rajah 2 menunjukkan paparan beberapa halaman yang terdapat dalam Komik STEM

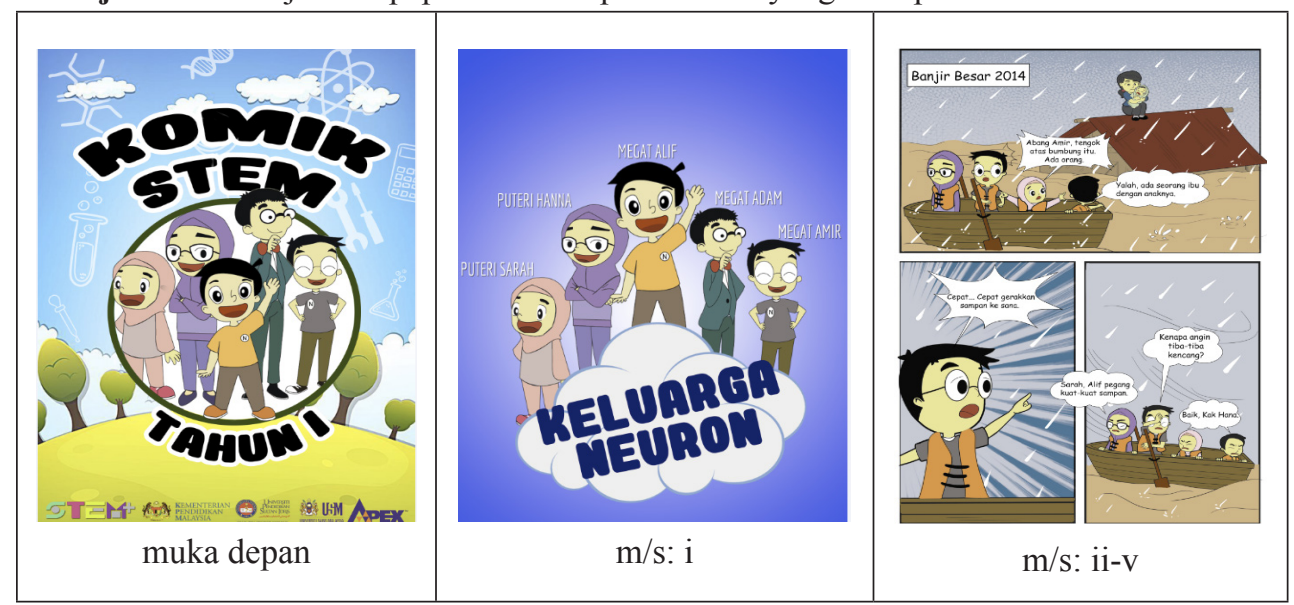




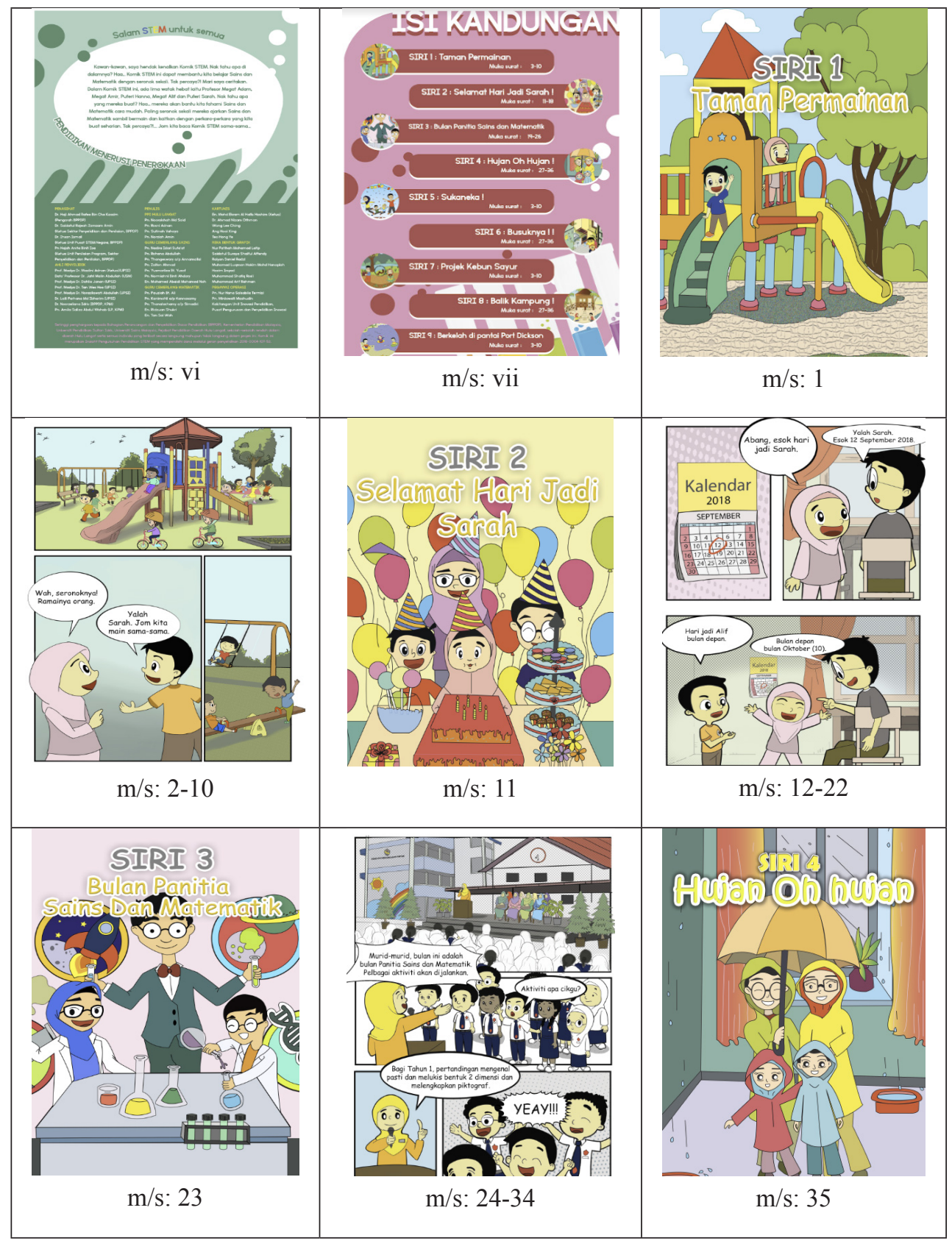




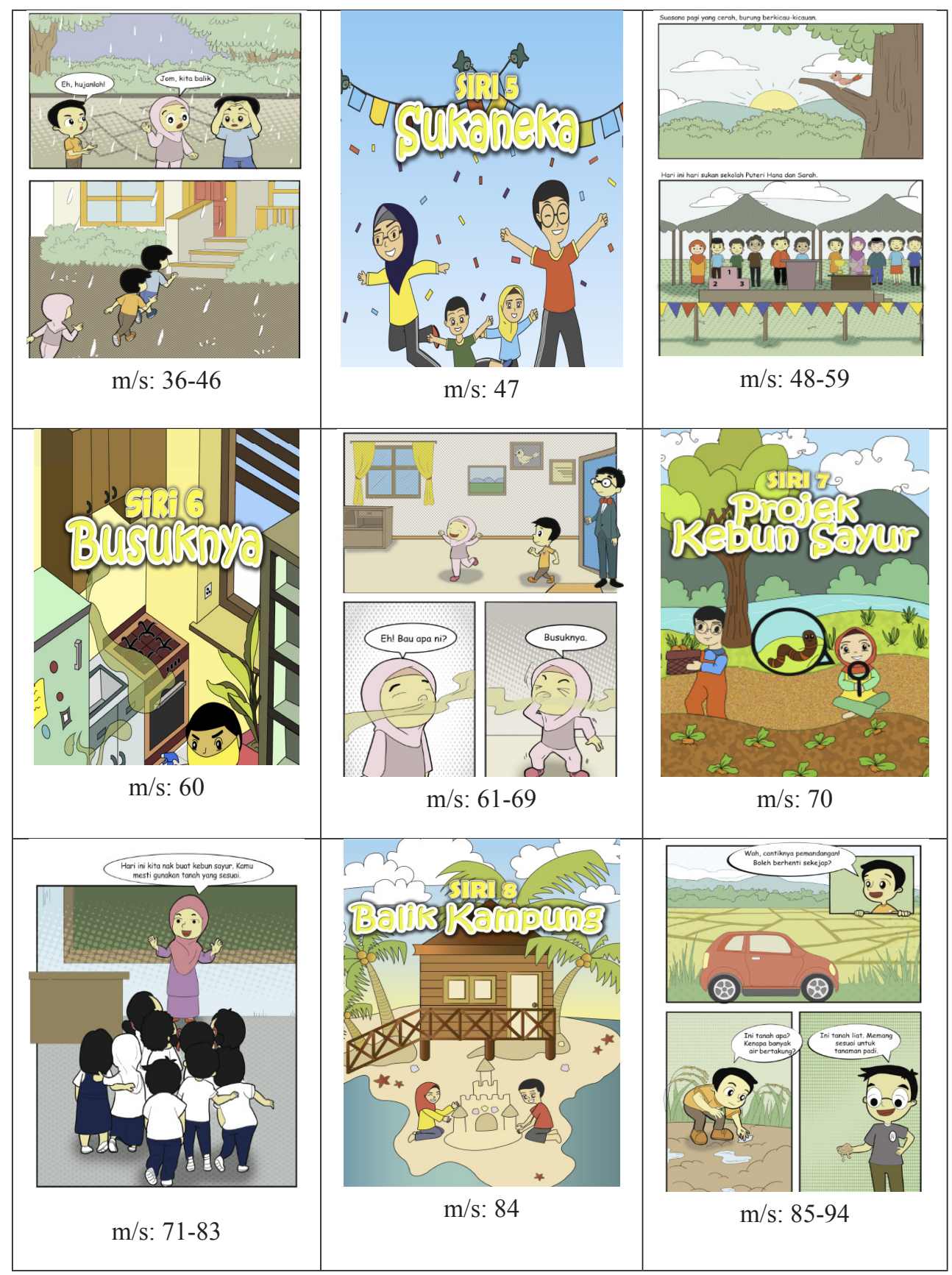




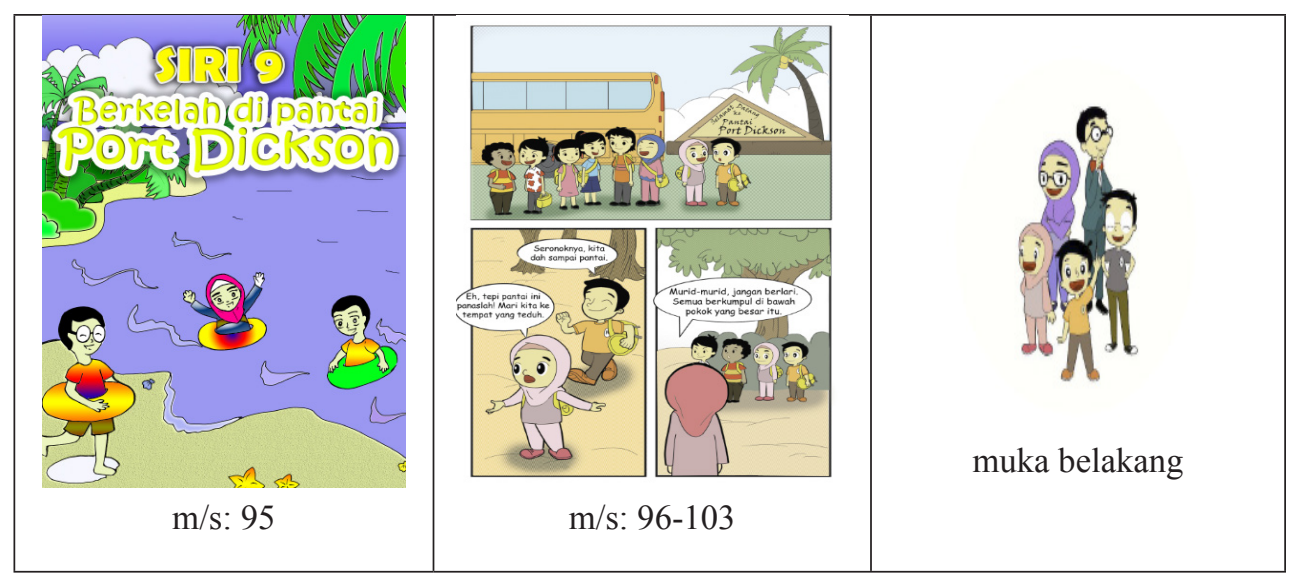

Rajah 2 Halaman dalam Komik STEM

\section{KESIMPULAN}

Bagi memastikan kandungan Komik ini mencapai kesahan yang baik, seramai empat orang panel penilai dari pelbagai sektor seperti bahagian kurikulum, lembaga peperiksaan dan pengurusan akademik telah terlibat dalam memberikan komen, maklum balas dan penilaian respon terhadap semua siri komik yang dibangunkan. Hasil daripada penilaian panel penilai menunjukkan bahawa komik yang dibangunkan adalah menepati objektif dan boleh dilaksanakan dengan baik. Dapatan daripada panel penilai turut bersetuju bahawa semua siri komik yang dihasilkan dapat dilaksanakan dan bersesuaian dengan kumpulan sasaran. Ini bermakna, semua siri dan tema yang terdapat dalam komik STEM yang dihasilkan berada pada tahap yang baik dan memuaskan. Adalah diharapkan Komik STEM ini dapat dijadikan bahan rujukan tambahan kepada murid-murid tahun satu agar ianya dapat membantu meningkatkan minat dan pencapaian murid terhdat mata pelajaran sains dan matematik.

\section{PENGHARGAAN}

Kajian ini adalah daripada Geran Penyelidikan Luar Bahagian Perancangan dan Penyelidikan Dasar Pendidikan (BPPDP), Kementerian Pendidikan Malaysia (KPM), kerjasama Antara Universiti Pendidikan Sultan Idris dan Universiti Sains Malaysia (Kod Penyelidikan: 2018-0004-107-52). Terima kasih kepada semua yang terlibat.

\section{RUJUKAN}

Brophy, S., Klein, S., Portsmore, M., Rogers, C. 2008. Advancing engineering education in P-12 classrooms. Journal of Engineering Education, 97(3) 369-387.

Boatright, M. D. 2010. Graphic journeys: Graphic novels' representations of immigrant experiences. Journal of Adolescent \& Adult Literacy, 53: 468-76.

Cleaver, S. 2008. Comics and graphic novels. Instructor, 117 (6), $28-30$ 
Chipman, I. 2010. Graphic novels with science and math themes. Book Links 106(19-20): 8-10.

Czerniak, C.M., Weber, W.B., Sandmann, Jr. A., \& Ahern, J. 1999. Literature review of science and mathematics integration. School Science and Mathematics, 99(8), $421-430$.

David, W. W. 2014. What Is STEM Education and Why Is It Important? Florida Association of Teacher Educators Journal, 1(14): 1-9. EDUCATION AT A GLANCE 2010: OECD INDICATORS ISBN 978-92-64-055988 (C) OECD 2010.

Judy, B. 2011. Five innovations from world war II. Retrieved from

http://bigdesignevents.com/2011/09/innovations-from-world-war-ii/

Gavigan, K., \& Kimmel, S. C. 2013. Graphic Novels, Comics, and the Common Core : Using Graphic Novels Across the Elementary Curriculum.

Jamaludin Ahmad. 2002. Kesahan, kebolehpercayaan dan keberkesanan komik program maju diri ke atas motivasi pencapaian di kalangan murid sekolah menengah negeri Selangor. Tesis PhD. Universiti Putra Malaysia.

Jeffries P. R. 2007. Simulation in Nursing Education: From Conceptualization to Evaluation. New York: National League of Nursing.

Lynn, A. B., Tamara, J. M., Carla, C. J. \& Gillian, H. R. 2016. Integrated STEM Education. STEM Road Map: A Framework for Integrated STEM Education. Taylor and Francis Inc. pp 23-37.

Mazlini Adnan, Aminah Ayob, Ong Eng Tek, Mohd Nasir Ibrahim, Noriah Ishak \& Jameyah Sheriff. 2016. Memperkasa pembangunan modal insan Malaysia di peringkat kanakkanak: Kajian kebolehlaksanaan dan kebolehintegrasian pendidikan STEM dalam kurikulum PERMATA Negara, GEOGRAFIA OnlineTM Malaysian Journal of Society and Space 12(1), 29 - 36.

Morrison, J. 2006. TIES STEM education monograph series, attributes of STEM education. Teaching Institute of Essential Science. Retrieved from https://www. partnersforpubliced.org/uploadedFiles/TeachingandLearning/Career and Technical Education/Attributes $\% 20$ of $\% 20$ STEM $\% 20$ Education $\% 20$ with $\% 20$ Cover\%202\%20.pdf

Miller, S. 2005. Developing and promoting graphic novel collections. Neal Schuman Pub.

Mohd Majid Konting. 2000. Kaedah Penyelidikan Pendidikan. Kuala Lumpur: Dewan Bahasa dan Pustaka.

Rodger W. B. 2013. The Case for STEM Education: Challenges and Opportunities. NSTA Press Book.

Sanders, M. 2009. STEM, STEM Education, STEMmania. December/January 2009. The Technology Teacher.

Schwarz, G. E. 2002. Graphic Novels for Multiple Literacies. Journal of Adolescent \& Adult Literacy, 46(3), 262-265. http://doi.org/10.2307/40017133

Song, J. 2008. Awakeing: Evolution of China's science and technology policies. Technology in Scinece, 30, 235-241. 
Steck T.R., DiBiase W., Wang C. \& Boukhtiarov A. 2015. The use of open-ended problem-based learning scenarios in an interdisciplinary biotechnology class: Evaluation of a problem-based learning course across three years. Journal of Microbiology \& Biology Education 13(1): 2-10. doi:10.1128/jmbe.v13i1.389.

Tabachnik, S. E., ed. 2009. Teaching the graphic novel. New York: Modern Language Association

Tilley, C.L. 2008. Reading comics. School Library Media Activities Monthly, 24 (9), $23-26$.

Yuan, G. 2013. Consultant Report Securing Australia's Future STEM: Country Comparisons, Report on China's STEM System. Australian Council of Learned Academies (ACOLA).

Zhong, X.-W., \& Yang, X.-D. 2007. Science and technology policy reform and its impact on China's national innovation system. Technology in Scinece, 29, 317325. 